DOI 10.5216/ia.v45i3.65124

\title{
LITERATURA E ENSINO DE ESPANHOL COMO LÍNGUA ESTRANGEIRA: LIVROS DIDÁTICOS E FORMAÇÃO DE PROFESSORES EM PERSPECTIVA
}

\author{
Augusto Moretti de BARROS \\ KÁtia RodRIGUES MELLO MIRANDA \\ Universidade Estadual Paulista (UNESP), Assis, São Paulo, Brasil
}

\begin{abstract}
Resumo: Este trabalho discute contribuições da literatura para o ensino de língua estrangeira, na formação e na atuação de professores, a partir de duas pesquisas: uma de Mestrado, que analisou duas coleções de livros didáticos para o ensino de língua espanhola; e um projeto docente que focou na atuação de graduandos em Letras/Espanhol durante seu estágio em um centro de línguas estrangeiras. As pesquisas se interseccionam pela perspectiva de que o texto literário pode contribuir significativamente para o ensino de línguas, uma vez que apresenta elementos linguísticos, culturais, sociais e históricos. As investigações pautaram-se na revisão bibliográfica sobre o ensino de espanhol/LE no Brasil e na pesquisa-ação qualitativa (LÜDKE; ANDRÉ, 2013; THIOLLENT, 2011). Constatou-se que o amplo potencial da literatura ainda não é suficientemente explorado em sala de aula, assim como nos livros didáticos, que mantêm uma abordagem superficial e de caráter utilitarista, fator que corrobora a relevância dessa discussão.
\end{abstract}

Palavras-chave: Ensino de Espanhol como Língua Estrangeira. Literatura. Formação Docente. Livros Didáticos.

\section{PALAVRAS INICIAIS}

Embora a abordagem significativa do texto literário em sala de aula e em materiais para o ensino de língua constitua uma preocupação antiga, e dela sigam decorrendo trabalhos importantes e necessários para o aperfeiçoamento das práticas docentes, a discussão de tal tema se revela longe de ser esgotada, considerando tanto o âmbito de ensino de língua materna como de estrangeira.

Sob esse prisma, o presente artigo reúne reflexões sobre o trabalho com o texto literário no ensino de espanhol como língua estrangeira (E/LE) a partir de dois contextos: a pesquisa acerca da prática de professores de espanhol em formação inicial e a análise de livros didáticos. Esse recorte integra discussões empreendidas em duas pesquisas de maior envergadura: uma dissertação de Mestrado desenvolvida no Programa de PósGraduação em Letras da Universidade Estadual Paulista (UNESP), campus de Assis, que teve como finalidade principal analisar a presença de textos literários hispanoamericanos e o espaço reservado a eles em duas coleções selecionadas pelo Programa Nacional do Livro Didático (PNLD) de 2011, com circulação nos três anos seguintes, para o ensino de língua espanhola: "Síntesis" (2012) e "Enlaces" (2010); e um projeto trienal docente vinculado ao Departamento de Letras Modernas também da UNESP-Assis, 
desenvolvido no âmbito de orientação e supervisão da prática de alunos-professores do Centro de Línguas e Desenvolvimento de Professores (CLDP).

Em consonância com o pensamento de Antonio Candido $(1972 ; 2017)$ sobre o papel primordial de humanização da literatura e sua correspondência a um direito de todos, concordamos que "sua função educativa é muito mais complexa do que pressupõe um ponto de vista estritamente pedagógico" e que a literatura "age com o impacto indiscriminado da própria vida e educa como ela, - com altos e baixos, luzes e sombras. [...] é um dos meios por que o jovem entra em contato com realidades que se tenciona escamotear-lhe" (CANDIDO, 1972, p. 84-85).

Considerando o âmbito de ensino e aprendizagem de línguas estrangeiras (LEs), acreditamos, também, que o trabalho com o texto literário pode contribuir para a prática integrada das quatro habilidades do aprendiz e para o desenvolvimento da aprendizagem autônoma (BENEDETTI, 2001). De tal modo, o resultado vai muito além da otimização das competências leitora, escrita, auditiva e oral, proporcionando ao estudante o contato mais profundo com um universo cultural complexo, dinâmico e variado por meio da literatura em LE.

As pesquisas referidas, desenvolvidas em período concomitante e na mesma instituição, tinham o objetivo comum de contribuir para os estudos sobre a relação entre a literatura e o ensino de E/LE. Além disso, os pesquisadores participaram indireta e diretamente da trajetória das duas investigações, com colaborações mútuas, gerando a possibilidade de sua aproximação e complementaridade.

Sendo assim, apresentamos, neste artigo, o percurso das investigações em pauta, abordando seus contextos, suas problematizações e seus resultados, com o intuito de que nossas reflexões contribuam para as discussões da área, além de ensejar novas indagações.

\section{LITERATURAS HISPANO-AMERICANAS: REPRESENTAÇÕES EM LIVROS DIDÁTICOS DE E/LE}

A pesquisa que resultou na dissertação de Mestrado em questão neste artigo advém da necessidade de analisar a forma como a literatura escrita em língua espanhola é introduzida e abordada em livros didáticos produzidos para o ensino de E/LE. Nas últimas décadas, é crescente o número de estudantes desse idioma em universidades brasileiras, assim como em escolas e centros de línguas, devido à participação do Brasil no Mercado Comum do Sul (Mercosul), além da chamada "Lei do Espanhol" (Lei $11.161 / 2005)^{1}$. Com isso, também aumentou o número de materiais produzidos com a finalidade de ser um apoio a esses estudos. Barros e Costa (2010) destacam a relevância dos materiais didáticos no contexto educacional, ressaltando que eles se configuram como "ferramentas de trabalho do professor; sem eles, podemos afirmar, as possibilidades de desenvolvimento do processo de ensino/aprendizagem reduzem-se drasticamente" (p. 88).

Compreendemos por material didático "todas as obras cuja intenção original é

1 A Lei 11.161/2005 foi revogada pela Medida Provisória 746 de 2017, que posteriormente se converteu na Lei 13.415/2017.

Inter-Ação, Goiânia, v.46, n.1, p. 409-421, jan./mar. 2021. Disponível em: <http://dx.doi.org/10.5216/ia.v45i3.65124>. 
explicitamente voltada para o uso pedagógico e essa intenção é manifestada pelo autor ou pelo editor" (UNIVERSIDADE DE SÃO PAULO, 2005, p. 7). Com isso, a definição elaborada pela Universidade de São Paulo (USP) abrange livros didáticos, paradidáticas, dicionários, coleções paradidáticas, dicionários, enciclopédias, coletâneas de textos literários produzidas para essa finalidade, entre outros materiais. Na pesquisa de Mestrado, concentramos as discussões e análises apenas nos livros didáticos, especificamente em duas coleções, que serão delimitadas adiante. O livro didático que se pauta na perspectiva cultural necessita apresentar um projeto de trabalho que desperte a atenção dos alunos para o respeito a toda a diversidade linguística e cultural daquelas comunidades, por meio de uma seleção atenta dos recursos textuais e visuais que o compõem, no que tange à origem e à abordagem desses materiais, para, assim, cumprir sua função pedagógica (BARROS, 2018).

Mais de vinte países têm o espanhol como idioma oficial. Buscando um recorte para a discussão pretendida, foram enfocados os escritores e as obras produzidas no continente americano, uma vez que tal área compreende a maioria dos falantes nativos de espanhol e que também produzem a maior quantidade de literatura nesse idioma. De tal maneira, nesse território geográfico, em que também estamos inseridos, múltiplas culturas se encontraram e seguem se encontrando. Sendo assim, acreditamos que um livro didático de E/LE deve ter como um de seus principais objetivos a composição de uma identidade cultural hispano-americana (BARROS, 2018) e que respeite as características particulares de seus povos, o que pode ocorrer com a inserção de amostras artístico-culturais produzidas por autores de variados contextos da América Hispânica.

A formação da identidade hispano-americana ocorreu a partir do contato entre diversas culturas que se mesclaram em suas semelhanças e diferenças, evidentemente, de maneira conflituosa. A heterogeneidade cultural da América Hispânica é caracterizada pelo processo de contato com o outro, o que a torna rica e complexa. Visto que há três elementos basilares e indissociáveis que compõem os aspectos culturais língua, literatura e o próprio conceito de cultura -, o acesso de um aprendiz a um livro didático de E/LE deve explorar esses elementos dos países hispanófonos (BARROS, 2018). Em tal processo, é fundamental reconhecer que o aluno ocupa uma posição de sujeito social que está em contato com o outro que, por sua vez, também possui um papel constituído através de interações com outros "outro" (SPIELMANN, 2000). Portanto, revela-se que as relações entre as diferentes manifestações sociais hispanoamericanas deram origem à identidade cultural que os livros didáticos devem refletir.

Diante desse cenário, a base do corpus selecionado para a pesquisa corresponde a duas coleções de livros didáticos elaborados para o ensino e a aprendizagem de E/LE: "Síntesis: curso de lengua española" (2012), de autoria do professor Ivan Martin, com publicação pela Editora Ática; e "Enlaces: español para jóvenes brasileños" (2010), coleção organizada por Soraia Osman, entre outras autoras, e publicada pela Editora Macmillan. Alguns pontos unem as duas coleções e justificam suas escolhas, como o fato de que ambas foram aprovadas pelo edital de 2012 do PNLD, com publicação no ano anterior e foram distribuídas até 2014, completando o ciclo de três anos. Outra característica comum entre os materiais é que são constituídos por três volumes, pensados para corresponder aos três anos do Ensino Médio. As coleções propõem, ainda, desde a sua apresentação, o trabalho com aspectos que destaquem a 
diversidade cultural dos países da América Hispânica a partir de variados recursos que possam simbolizar essas culturas. Com o objetivo de verificar se o proposto se concretiza na elaboração dos materiais, realizamos a análise da presença de elementos literários e da representação de cultura que eles apresentam.

A coleção "Síntesis" (MARTIN, 2012) possui, ao todo, vinte e três textos literários de escritores hispano-americanos, sendo quinze deles escritos por autores argentinos ou uruguaios. Por sua vez, a coleção "Enlaces" (OSMAN et al., 2010) apresenta cinco textos literários produzidos na América Hispânica, tendo dois autores argentinos e um uruguaio dentre eles. Ainda que os autores dos livros didáticos busquem inserir textos de escritores de variados contextos de vida e de produção, observamos que a maioria pertence a autores advindos de países do extremo sul da América, a região chamada rioplatense (que ganha o status de comunidade de prestígio linguístico e literário): Argentina e Uruguai. É o caso, por exemplo, dos escritores Julio Cortázar, Jorge Luis Borges, Eduardo Galeano e Mario Benedetti, entre outros. Tal seleção pode se justificar pelo fato de que esses países são membros do Mercosul, o que amplia as relações comerciais e os intercâmbios culturais com o Brasil. Essa seleção pouco variada é problemática, visto que o aprendiz que tiver esse livro como apoio didático vai estar em contato com poucas representações literárias e linguísticas.

Notamos também que a grande maioria desses autores viveu e produziu no século XX e que as suas obras são consideradas canônicas, fato que Ihes atribui um status de privilégio em diversos contextos, entre eles, nas escolhas de textos representativos para fins didáticos (BARROS, 2018). Assim, destacamos a falta de espaço destinado às manifestações literárias das margens, o que configura mais um ponto adverso. Uma vez que o recorte literário feito contempla o cânone, os materiais ao menos poderiam haver apresentado uma maior variedade em relação ao contexto de produção desses textos, como a inserção do mundialmente conhecido escritor chileno Pablo Neruda, ganhador do Prêmio Nobel de Literatura em 1971, e o reconhecido autor peruano Mario Vargas-Llosa, também laureado com esse grande Prêmio, no ano de 2010.

Outro aspecto que merece destaque já fora assinalado por Lajolo desde os anos 1980: o texto literário, quando presente no ensino de línguas, ainda ocupa uma posição de pretexto para o ensino do idioma ou de determinadas características formais da literatura. Em casos como esses, segundo a autora, o trabalho com o texto literário não será significativo para o aluno, mesmo que ele responda a todos os exercícios relacionados com o texto de maneira satisfatória. Dessa maneira, o efeito possivelmente será o contrário do esperado: em vez de o aluno se sentir próximo do texto literário por conhecê-lo em uma atividade de estudo de língua, poderá criar uma barreira que o impedirá de ler tal texto sem um roteiro prévio que encaminhe a leitura para determinadas finalidades (LAJOLO, 2009).

O livro didático adotado por um órgão, por uma instituição, por professores ou por qualquer outra instância é carregado de ideologia, já que é composto por seleções feitas por seu(s) organizador(es) a partir de critérios estabelecidos por ele(s) ou pelo contexto em que se insere essa produção, o que pode refletir a sua bagagem sobre o assunto e a sua perspectiva linguística, pedagógica, política, social, cultural, entre outras. 
O Guia do PNLD de 2012, ano de aprovação das coleções analisadas, informa que a escolha dos materiais se pautou na perspectiva sociocultural e intercultural demonstrada por eles, já que um dos critérios de seleção previstos no edital é reconhecer se as coleções apresentam "diversidade étnica e cultural das comunidades das regiões e dos países em que a língua estrangeira é falada" (BRASIL, 2011, p. 12). Sendo, então, um apoio pedagógico, o livro didático deve voltar-se a estimular o aprendiz a conhecer o outro e a respeitar as diferenças, princípios já exigidos pelo PNLD. Já a palavra "literatura" não consta dos pressupostos do Guia para a seleção dos livros didáticos, apenas na análise feita sobre as coleções quando se discute a sua presença.

Os contextos elaborados pelos autores dos livros didáticos estudados, para incluir os textos literários, são, em sua grande maioria, propostas de exercícios que não incentivam o aprendiz a arriscar análises mais aprofundadas desses textos e que desenvolvam sua autonomia como leitor. Um exemplo que ilustra tal situação na coleção "Síntesis" (MARTIN, 2012) é quando apresenta, em seu terceiro volume, o poema "Encargo", do escritor argentino Julio Cortázar, e uma série de exercícios de cunho gramatical que abordam a formação e o uso do imperativo, sem ao menos se aproximar do texto enquanto gênero literário. Já o terceiro volume da coleção "Enlaces" (OSMAN et al., 2010) contém um exercício que se restringe à abordagem de expressões e construções linguísticas estudadas na unidade didática aplicadas ao poema "Canción", do poeta cubano Nicolás Guillén.

O direcionamento dado pelas atividades, por vezes, acaba por delimitar as possibilidades do aluno, sobretudo nos momentos em que as manifestações literárias funcionam como base para o estudo de estruturas gramaticais aplicadas a contextos e para exemplificação de pronúncia, ou como modelo de tipos textuais. Por conseguinte, embora exista uma série de vantagens em haver o estudo estrutural no processo de aprendizagem, os textos são configurados nesse estilo de proposta de atividades, prescindindo de um trabalho atrelado a discussões sobre os elementos culturais, que pode colaborar para que o aluno se constitua um cidadão e um leitor com potencialidade crítica.

Centro de línguas E DESEnVOlVimento de PROFESSORES: CONTEXTO DE ENSINO, APRENDIZAGEM, PRÁTICA E PESQUISA

A pesquisa docente compreendeu uma experiência junto ao Centro de Línguas e Desenvolvimento de Professores (CLDP) na UNESP de Assis, configurada no projeto trienal "A literatura no ensino de espanhol como língua estrangeira: um estudo a partir da prática de professores em formação inicial", desenvolvido entre 2015 e 2017 (MIRANDA, 2018). O projeto docente atendeu a uma demanda da Área de Espanhol do Departamento de Letras Modernas, especialmente empenhada em colaborar na orientação e supervisão de alunos estagiários após a implementação do referido Centro de Línguas, conectando tal ação a nossos estudos de pós-graduação em literatura. Assim, sua finalidade geral foi contribuir para a prática inicial desses alunos da graduação em Letras-Espanhol da UNESP-Assis, professores estagiários do CLDP, ampliando as discussões no espaço de supervisão e consultoria, com o incentivo da inserção da literatura nas aulas de língua espanhola.

O CLDP é um projeto de extensão colaborativo entre o Departamento de Letras 
Modernas e o Departamento de Estudos Linguísticos, Literários e da Educação da UNESP-Assis, com o apoio da PROEX (Pró-Reitoria de Extensão), em funcionamento desde 2010, com uma equipe administrativa composta por coordenação, vicecoordenação e docentes encarregados da consultoria das línguas ministradas (Alemão, Espanhol, Francês, Inglês, Italiano, Japonês, Mandarim, Grego e Português para estrangeiros).

Os cursos de línguas são oferecidos em diferentes níveis - geralmente, do básico ao avançado - e ministrados por alunos da graduação em Letras selecionados por seu desempenho acadêmico, como parte do estágio de regência em LE. De tal forma, o CLDP viabiliza um espaço profícuo para que esses estudantes, em seu processo de formação inicial, efetuem seus estágios com o respaldo e acompanhamento dos docentes, em reuniões de orientação e supervisão realizadas periodicamente. Tal configuração constitui um diferencial, já que, ao mesmo tempo em que prima pelo oferecimento de cursos de qualidade, o CLDP também atende ao objetivo de ser um espaço para o desenvolvimento de professores de LEs.

As matrículas para os cursos de línguas ocorrem a cada início de semestre, de acordo com o calendário letivo da graduação, e são abertas à comunidade interna e externa ao campus, com faixa etária entre 12 e 50 anos. No caso do espanhol, por semestre, há, em geral, quatro turmas de até 20 alunos, cada uma ministrada em parceria por uma dupla de alunos estagiários, com dois encontros semanais de $1 \mathrm{~h} 40$ cada. Sendo assim, o projeto docente contou com a participação de estudantes do curso de graduação em fase de estágio supervisionado e, por extensão, de alunos matriculados nos cursos de Língua Espanhola oferecidos pelo CLDP.

Tendo em vista a importância do ensino e da aprendizagem de LEs, bem como as demandas atuais da carreira docente, reconhecemos a necessidade de que a prática inicial atrelada aos cursos de graduação seja cuidadosamente planejada e executada, de maneira que "o futuro professor conclua seu curso com uma visão ampla e ao mesmo tempo profunda das principais questões relativas ao idioma e ao seu ensino" (ERES FERNÁNDEZ, 2008, p. 280). Logo, é essencial que os cursos de formação, mais do que simplesmente habilitar, capacitem os futuros professores à realização de um trabalho de qualidade.

Acreditamos que a experiência no ensino de língua espanhola e literaturas hispânicas, bem como a visão de que a literatura, com seu poder de agregar cultura, arte, contextos sociais, valores humanos etc., constituem um viés muito significativo para o ensino e a aprendizagem de LEs. A partir dessa perspectiva, buscamos, nas reuniões de orientação e supervisão dos professores estagiários de espanhol do CLDP, ampliar o espaço de diálogo e reflexão, articulando discussões acerca da relevância do texto literário nas aulas de E/LE.

Nessa direção, o projeto docente considerou a necessidade de desenvolvimento de um professor cuja postura valorize e busque o engajamento de seus alunos em atividades reflexivas por meio da linguagem e, assim, empreenda em suas aulas de E/LE um trabalho com textos literários dentro de uma perspectiva discursiva e não meramente formal ou conteudista.

O desenvolvimento da proposta se pautou nos pressupostos da metodologia 
BARROS, A. M. de; MIRANDA, K. R. M.

qualitativa (LÜDKE; ANDRÉ, 2013), em sua modalidade de pesquisa-ação, e os procedimentos de análise dos dados tiveram caráter interpretativista. A pesquisa-ação é

\begin{abstract}
um tipo de pesquisa social com base empírica que é concebida e realizada em estreita associação com uma ação ou com a resolução de um problema coletivo e no qual os pesquisadores e os participantes representativos da situação ou do problema estão envolvidos de modo cooperativo ou participativo (THIOLLENT, 2011, p. 20).
\end{abstract}

Nesse tipo de pesquisa, há a ênfase no processo, a preocupação em retratar o ponto de vista dos participantes e a fonte direta dos dados corresponde ao ambiente natural. Para a organização e coleta de dados, além do diálogo reflexivo constante com os alunos-professores nos encontros de supervisão, foram produzidas por eles fichas de relato sobre suas experiências em sala de aula a partir do trabalho com textos literários. $\mathrm{Na}$ supervisão, ainda ponderamos com eles quanto a essa ficha, a fim de que a considerassem não somente como um simples instrumento de registro, mas, sobretudo, como uma oportunidade de sistematização e reflexão sobre a sua prática docente.

As principais perguntas de pesquisa delineadas foram: (Como) a literatura está presente nas aulas de E/LE do CLDP? Em que medida a literatura pode contribuir para o aprendizado de uma LE? Que dificuldades se impõem à presença da literatura em aulas de E/LE do CLDP? De que maneiras a literatura pode integrar significativamente o ensino de E/LE? Tendo em vista esses questionamentos basilares, apresentamos a seguir uma amostragem da análise efetuada no desenvolvimento do projeto.

Ao longo do triênio, foi possível constatar que a maior parte dos alunosprofessores não havia levado textos literários para suas aulas de $E / L E$ antes que houvesse, nos encontros de supervisão, uma reflexão conjunta a esse respeito e a consequente motivação para tal trabalho. Esse dado, que, dentre outros fatores, assinala a manutenção de uma ótica que dissocia língua e literatura, foi debatido nos encontros de supervisão, a fim de estimular os estagiários ao diálogo e provável redimensionamento dessa visão.

A rotatividade de alunos-professores ao longo dos semestres foi um dos impasses encontrados, por configurar o acompanhamento do trabalho com os textos literários em períodos mais curtos (em geral, um semestre). De qualquer modo, foi possível promover a conscientização acerca da importância da literatura no ensino de E/LE e de quão significativa é sua presença nas aulas, bem como fomentar a desconstrução de crenças equivocadas que permeiam o ensino de línguas, como a da dissociação entre língua e literatura.

Durante o período de execução do projeto docente, em cada início de semestre letivo do CLDP era proposto aos alunos-professores que levassem um ou mais textos literários em pelo menos três aulas - consecutivas ou não -, a fim de que houvesse uma sequência razoável para a observação progressiva da resposta ao trabalho desenvolvido com a literatura em sala de aula. Também foi acordado que, após cada aula, seria produzida uma ficha (da qual todos os professores tinham um modelo comum) para o relato reflexivo dessas aulas, e que tais fichas seriam posteriormente compartilhadas com a professora supervisora e os demais colegas estagiários da área de espanhol para, nos encontros periódicos de supervisão, serem discutidas e analisadas conjuntamente 
ao longo do semestre. Dessa maneira, todos tinham oportunidade de divulgar seu relato escrito, além de comentar oralmente as experiências vivenciadas, assim como acessar, dialogar e intercambiar ideias com os colegas sobre o trabalho desenvolvido. No encontro final de supervisão de cada semestre, as fichas eram compiladas e novamente examinadas pelo grupo de professores estagiários, para uma reflexão conjunta sobre o trabalho consolidado com a literatura nas aulas de E/LE.

A seleção dos textos e o modo como seriam trabalhados nas aulas foram de livre escolha dos professores estagiários e, em síntese, revelaram a consideração de diversos critérios, como gosto pessoal, popularidade do escritor, temas específicos, estética e variedade de tipologias (poemas, capítulos de romances, microrrelatos, lendas e contos de fadas). Para exemplificação, vão a seguir excertos de alguns relatos constantes das fichas produzidas pelos professores estagiários, que justificam a escolha do texto literário:

(01) pelos sentidos dos seus conteúdos e maneiras de os comunicarem, passíveis de diferentes interpretações.

(02) Elegimos "Preámbulo a las instrucciones para dar cuerda al reloj", de Julio Cortázar, por cuestionar y agregar valores a cosas sencillas, como el reloj. $Y$ también por el gran aporte intelectual ofrecido por el escritor al escribir las instrucciones que huyen a un género literario, o sea, innova al describir acciones diarias y explicarlas de modo a [sic] que cualquiera las produzca.

Como é possível verificar, o segundo fragmento enseja a oportunidade de aproximação entre o leitor e o texto literário selecionado para a aula de E/LE, o qual, dentre outros aspectos, permite ao estudante a percepção de que ele também pode produzir textos a partir de temas cotidianos, utilizando as estruturas linguísticas que domina, por mais simples que sejam.

No tocante às atividades delineadas para o trabalho em sala de aula, seus objetivos e caminhos de execução, boa parte das fichas denotou o intuito e o empenho dos professores em realizar propostas que instigassem a exploração sensível, atenta e proveitosa do texto literário, conforme demonstram os seguintes relatos:

(03) A intenção é a de no processo das atividades os alunos desenvolverem a partir de marcas textuais o compartilhamento do trabalho em equipe, as práticas da pronúncia e escrita, o estímulo da criatividade e de análises críticas, a abrangência de vocabulários e a observação de verbos no Presente do Indicativo. Nós, professoras em formação, pretendemos assim oferecer a oportunidade conjunta da elaboração e prática de atividades, assim como criar um domínio maior de conteúdos e diálogos entre as matérias de nossas grades curriculares.

(04) O objetivo dos poemas era trabalhar a leitura e pronúncia dos alunos, ao lerem o poema, identificando as palavras conhecidas e fazendo revisão do vocabulário para interagirem com o assunto. Os textos utilizados em sala são simples, com possível entendimento. Mas, traduzíamos para que fizessem uma compreensão do tema e 
BARROS, A. M. de; MIRANDA, K. R. M.

propusemos construírem pequenas frases com algumas palavras do poema para treinar a escrita.

(05) [...] Depois de discutir as duas atividades, passamos e discutimos o poema "Niño de la calle" para completar e encerrar o assunto de modo a sensibilizar os alunos para o tema tratado.

Esses relatos assinalam, ainda, que as atividades propostas, em alguns momentos, apresentam finalidades mais abrangentes e de perfil decodificativo, sem requerer uma exploração de sentidos ou associações mais apuradas. Tais aspectos também eram assinalados e analisados, de maneira construtiva e conjunta, nos encontros de supervisão com os professores estagiários, que buscavam superar essas lacunas em propostas posteriores. Os relatos quatro e cinco, que são de uma mesma dupla de estagiárias, a respeito de atividades propostas com um intervalo de tempo entre elas, configuram um exemplo de alcance dessa evolução, uma vez que a atividade aludida no quinto excerto destaca o intuito de despertar a sensibilidade dos estudantes a partir do texto literário. Dessa forma, é possível constatar que, ao longo da elaboração e da prática das atividades em sala de aula, os estagiários puderam ampliar sua reflexão sobre o trabalho com a literatura e aprimorá-lo.

Por fim, a maior parte das atividades priorizou - ou, ao menos, tencionou - um trabalho voltado para a exploração dinâmica e sensível do texto literário, aguçando a interpretação dos estudantes e promovendo seu envolvimento e identificação com os temas. Alguns professores estagiários relataram a realização voluntária, por seus alunos, de pesquisas sobre os autores trabalhados, assim como o interesse manifestado por eles em ler outros textos literários, após a execução das propostas com a literatura nas aulas. Uma das duplas pediu a seus alunos um retorno por escrito sobre a aula e ressaltou a seguinte resposta: “(06) Eu não gostava de literatura, mas a aula de hoje me proporcionou um entendimento melhor da literatura, afinal, eu nunca tinha imaginado que subir uma escada tinha toda essa reflexão e esse lado literário".

Ao final de cada semestre letivo do CLDP, os estagiários eram indagados sobre o impacto que a intervenção docente nas reuniões de supervisão, trazendo a proposta de inserção da literatura nas aulas de E/LE, teve em sua prática docente. As respostas oferecidas, das quais seguem alguns exemplos, apontam o proveito gerado pela realização do projeto ao desenvolvimento desses professores:

(07) A proposta de trabalhar com a literatura superou positivamente nossas expectativas. Os alunos se mostraram dispostos a participar das atividades e esses foram os dias em que as realizaram de maneira mais motivada e integrada com o grupo.

(08) Apresentamos um trecho do romance Como agua para chocolate e fizemos breves comentários [...] os alunos ficaram tão empolgados que combinamos de assistir ao filme para fazermos outros trabalhos em grupos. Emprestamos esta obra para uma aluna, que leu em uma semana e disse que a corresponde de tal maneira que é o livro de sua vida, seja pela poética e sentimentos ou pelas misturas de gêneros, como as receitas. Disse que cozinhou e leu ao mesmo tempo, como poeta e cozinheira. Descobrimos, assim, que a literatura se fez marcante para nossos alunos, pela relação com suas vidas. Isso nos fez repensar a elaboração de nossas 
aulas, em que passaremos a trabalhar mais com a literatura [...].

Sendo assim, acreditamos que o projeto empreendido contribuiu para o aprimoramento da formação docente inicial dos estagiários de espanhol do CLDP e, nessa esteira, para a ampliação da visão metodológica e emancipação desses profissionais, bem como para o desenvolvimento gradual de sua autonomia e capacidade crítico-reflexiva, requisitos do professor competente. Nessa dimensão, o espaço criado nos encontros de supervisão do CLDP para o compartilhamento de ideias, experiências, impasses e êxitos, não somente com a professora orientadora, mas com os demais colegas, mostrou-se muito enriquecedor para os estagiários, que também intercambiavam materiais, opiniões e sugestões, além de usufruírem da oportunidade de conscientizar-se sobre a permanente necessidade de reflexão, para a efetivação de uma prática docente significativa.

\section{CONSIDERAÇÕES FINAIS}

A finalidade neste artigo foi sistematizar algumas discussões e resultados de duas pesquisas acadêmicas confluentes e de maior porte, visto que ambas chegaram a conclusões também convergentes e versam sobre um tema de reiterada relevância. As investigações desenvolvidas se desdobraram em outros projetos: a dissertação de Mestrado gerou uma pesquisa de Doutorado, que está em andamento e tem como escopo o ensino de literaturas de língua espanhola no Ensino Superior; e da pesquisa docente derivaram-se projetos de iniciação científica, orientados pela docente pesquisadora e desenvolvidos no próprio CLDP, além da participação em bancas de trabalhos de mestrado dentro da temática de literatura e ensino de E/LE. Cabe mencionar, ainda, que o projeto docente atual prossegue com a reflexão sobre texto literário e ensino de línguas, estendendo sua abrangência para outro projeto de extensão e para o segmento da pós-graduação.

A importância do papel da leitura, sobretudo a literária, na formação do indivíduo como estudante e como ser humano deve ser constantemente ressaltada para que cresça, cada vez mais, a conscientização a esse respeito. O texto literário oferece ao leitor a oportunidade de conhecer outras realidades, outros costumes, outros povos, outros universos, ampliando sua visão de mundo, além de lhe possibilitar refletir sobre a sua posição no mundo, levando-o a rever sua maneira de encarar o outro, o diferente. Assim, retomando Candido (1972; 2017), ratificamos a imprescindível contribuição da literatura para a formação do homem e, por consequência, para as alterações positivas em suas relações sociais.

De acordo com o que defende Lajolo (2009), e com vistas à esfera de ensino e aprendizagem de LEs, concluímos que o texto literário, de maneira geral, ainda desempenha uma função pretextual. Na realização das pesquisas, desenvolvidas em contextos diferentes, foi possível averiguar que existem diversas ações e projetos que priorizam o trabalho significativo com a literatura no âmbito das LEs. Os resultados das análises, no entanto, demonstram que as contribuições na direção de desfazer a postura utilitarista no que tange ao tratamento do texto literário em sala de aula se apresentam 
BARROS, A. M. de; MIRANDA, K. R. M.

como uma necessidade constante.

Dessa maneira, esperamos ter despertado a atenção para a importância da relação estabelecida entre língua e literatura no ensino de LEs, contribuindo para uma formação e prática docente mais crítica, assim como para o manejo mais consciente de livros didáticos. Por fim, vale enfatizar que as investigações aqui apresentadas enfocam uma discussão que, ao contrário de encerrada, deve desdobrar-se em outras iniciativas.

Artigo recebido em: 19/08/2020

Aprovado para publicação em: 17/11/2020

LITERATURE AND TEACHING OF SPANISH AS A FOREIGN LANGUAGE: TEXTBOOKS AND TEACHER TRAINING IN PERSPECTIVE

ABSTRACT: This paper discusses contributions of literature to foreign language teaching, in the training and performance of teachers, based on two research projects: a Master's degree, which analyzed two collections of textbooks for teaching the Spanish language; and a teaching project that focused on the performance of undergraduate students in Letters/Spanish during their trainee period at a foreign language center. The research is intersected by the perspective that the literary text can contribute significantly to the teaching of languages, since it presents linguistic, cultural, social and historical elements. The investigations were based on the literature review on the teaching of Spanish as a Foreign Language in Brazil and on qualitative research-action (LÜDKE; ANDRÉ, 2013; THIOLLENT, 2011). The conclusion was that the broad potential of literature is not yet sufficiently explored in the classroom, neither in textbooks, which maintain a superficial and utilitarian approach, a factor that corroborates the relevance of this discussion.

KEYWORDS: Teaching Spanish as a foreign language. Literature. Teacher training. Textbooks.

LITERATURA Y ENSEÑANZA DE ESPAÑOL COMO LENGUA EXTRANJERA: LIBROS DIDÁCTICOS Y FORMACIÓN DE PROFESORES EN PERSPECTIVA

RESUMEN: Este trabajo discute contribuciones de la literatura para la enseñanza de lengua extranjera, en la formación y en la actuación de profesores, a partir de dos investigaciones: una de Maestría, que se ocupó de dos colecciones de libros didácticos para la enseñanza de lengua española; y un proyecto docente que enfocó la participación de estudiantes de Letras/Español durante su pasantía en un centro de lenguas extranjeras. Las investigaciones se cruzan en la perspectiva que el texto literario puede contribuir significativamente a la enseñanza de lenguas, una vez que presenta elementos lingüísticos, culturales, sociales e históricos. Las investigaciones se basaron en la revisión bibliográfica sobre la enseñanza del español/LE en Brasil y en la investigación-acción cualitativa (LÜDKE; ANDRÉ, 2013; THIOLLENT, 2011). Se constató que el amplio potencial de la literatura todavía no se explora suficientemente en la sala de clases, así como en los libros didácticos, que mantienen un abordaje superficial y de carácter utilitario, hecho que corrobora la relevancia de dicha discusión.

Inter-Ação, Goiânia, v.46, n.1, p. 409-421, jan./mar. 2021. Disponível em: <http://dx.doi.org/10.5216/ia.v45i3.65124>. 
PALABRAS CLAVE: Enseñanza de español como lengua extranjera. Literatura. Formación docente. Libros didácticos.

\section{REFERÊNCIAS}

BARROS, A. M. Representações literárias e culturais da América Hispânica em livros didáticos para o ensino de espanhol/LE. 2018. 325 f. Dissertação (Mestrado em Letras) - Universidade Estadual Paulista (UNESP), Faculdade de Ciências e Letras, Assis, 2018.

BARROS, C.; COSTA, E. Elaboração de materiais didáticos para o ensino de espanhol. In: BARROS, C.; COSTA, E. (Org.). Espanhol: Ensino Médio. Brasília: Ministério da Educação, Secretaria de Educação Básica, 2010. Coleção Explorando o Ensino, v. 16. Disponível em: http://portal.mec.gov.br/index.php?option=com_content\&view=article\&id=16903\&lte\% 20mid=1139. Acesso em: 15 jun. 2020.

BENEDETTI, A. M. El texto literario como motivador del aprendizaje autónomo. In: TROUCHE, A.; REIS, L. (Org.). Hispanismo 2000. Niterói: ABH, 2001. p. 65-68.

BRASIL. Guia de Livros Didáticos: PNLD 2012 - Língua Estrangeira Moderna. Brasília: Ministério da Educação, Secretaria de Educação Básica, 2011. Disponível em: https://www.fnde.gov.br/index.php/programas/programas-do-livro/pnld/guia-do-livrodidatico/item/2988-guia-pnld-2012-ensino-m\%C3\%A9dio. Acesso em: 18 jun. 2020.

CANDIDO, A. A literatura e a formação do homem. Ciência e Cultura, Campinas, v. 24, n. 9, 1972, p. 81-90.

CANDIDO, A. O direito à literatura. In: CANDIDO, A. Vários escritos. 6. ed. Rio de Janeiro: Ouro sobre azul, 2017. p. 171-193.

ERES FERNÁNDEZ, G. As transformações no mundo do trabalho e as implicações para a formação de professores de línguas. In: GIL, G.; ABRAHÃO, M. H. V. (Org.). Educação de professores de línguas: os desafios do formador. Campinas: Pontes, 2008. p. 275-281.

HIPOGROSSO, C.; ORLANDO, V. Nuevas formas de enseñanza de lenguas extranjeras ¿la literatura entre ellas? In: MASELLO, L. (Org.). Español como lengua extranjera: aspectos descriptivos y metodológicos. Montevideo: Universidad de La República, Departamento de Publicaciones, 2002, p. 29-55.

LAJOLO, M. O texto não é pretexto. Será que não é mesmo? In: ZILBERMAN, Regina; RÖSING, T. (Org.). Escola e leitura: velha crise, novas alternativas. São Paulo: Global, 2009. p. 99-112. 
BARROS, A. M. de; MIRANDA, K. R. M.

LÜDKE, M.; ANDRÉ, M. Pesquisa em educação: abordagens qualitativas. 2. ed. São Paulo: EPU, 2013.

MARTIN, I. Síntesis: curso de lengua española. São Paulo: Ática, 2012.

MIRANDA, K. R. M. A literatura no ensino de espanhol como língua estrangeira: um estudo a partir da prática de professores em formação inicial. Relatório de pesquisa docente. Assis: UNESP, 2018. mimeo.

OSMAN, S. et al. Enlaces: español para jóvenes brasileños. São Paulo: Macmillan, 2010.

SPIELMANN, E. "Alteridade" desde Sartre até Bhabha: um surf para a história do conceito. Revista de literatura comparada 5, Salvador: Abralic, 2000, p. 18-28.

THIOLLENT, M. Metodologia da pesquisa-ação. 18. ed. São Paulo: Cortez, 2011.

UNIVERSIDADE DE SÃO PAULO. Faculdade de Educação. Guia de preenchimento da ficha do banco de dados livres. São Paulo, 2005.

\footnotetext{
Augusto Moretti de Barros: Doutorando pelo Programa de Pós-Graduação em Letras, área de Literatura e Vida Social, da Universidade Estadual Paulista (UNESP), campus de Assis, e Mestre pelo mesmo programa. Professor-bolsista temporário de Língua Espanhola, pelo Departamento de Letras Modernas, no curso de graduação em Letras da UNESP-Assis. Integra o Grupo de Estudos e Pesquisas sobre Linguagem, Ensino e Narrativa de Professores (GEPLENP) e - Grupo de Pesquisa Narrativas Estrangeiras Modernas. Atua como pesquisador nas áreas de ensino de literaturas em língua espanhola, literatura e espanhol como língua estrangeira e livros didáticos. Orcid: https://orcid.org/0000-0002-7201-3009

E-mail: augusto.moretti@unesp.br

KátIa Rodrigues Mello Miranda: Professora Assistente Doutora da Universidade Estadual Paulista Júlio de Mesquita Filho - UNESP, campus de Assis. Mestre e Doutora em Letras pela mesma instituição. Integra os Grupos de Pesquisa Narrativas Estrangeiras Modernas, Grupo de Pesquisa em Estudos Hispânicos e Tradução, Léxico e Interculturalidade. É docente e pesquisadora do Programa de Pós-graduação PROFLETRAS. Atua como consultora e supervisora da área de língua espanhola nos projetos de extensão Centro de Línguas e Desenvolvimento de Professores (CLDP) e Universidade Aberta à Terceira Idade (UNATI), ambos da UNESP-Assis. Suas pesquisas concentram-se principalmente nas áreas de narrativa de autoria feminina, narrativa de extração histórica, literatura hispano-americana e latino-americana, literatura e ensino de língua, ensino $e$ aprendizagem de língua estrangeira (espanhol).

Orcid: https://orcid.org/0000-0002-2041-9795

E-mail:katia.mello@unesp.br
}

Este periódico utiliza a licença Creative Commons Attribution 3.0, para periódicos de acesso aberto (Open Archives Iniciative - OAI). 